\title{
Depression Visual Analogue Scale
}

National Cancer Institute

\section{Source}

National Cancer Institute. Depression Visual Analogue Scale. NCI Thesaurus. Code C141595.

A depression scale from 0 to 10 on which the patient marks the current level of depression experienced. 